J.Lake Sci. (湖泊科学), 2016, 28(1): 105-113

DOI 10. 18307/2016. 0112

(C) 2016 by Journal of Lake Sciences

\title{
典型城市河道氮、磷自净能力影响因素"
}

\author{
王蓉, 黄天寅䧆, 吴玮 \\ (苏州科技学院环境科学与工程学院, 苏州 215009)
}

\begin{abstract}
摘 要: 以典型城市河道 (苏州官渎花园内河) 为研究对象, 通过室内和室外模拟实验, 研究不同污染物浓度、流速、曝气 复氧、渗滤作用和温度对氮、磷自净能力的影响, 结果表明: 水体中氮、磷的自净作用受污染物浓度、流速、溶解氧浓度、温 度和微生物等多种因素的影响. 随着污染物浓度的增加, 氨氮和硝态氮降解速率增加, 而底泥中磷的总体吸附速率却增 大. 与静止水体相比, 模拟河道通过增加流速、曝气复氧、渗滤作用能增强水体氮磷的自净能力, 提高氮、磷降解速率. 其 中, 改变流速后自净参数氨氮和总磷增量分别为 $17.05 \%$ 和 $34.85 \%$; 曝气复氧后自净参数氨氮和总磷增量分别为 $8.35 \%$ 和 $59.33 \%$; 增加微生物量 (渗滤作用) 后自净参数氨氮和总磷增量分别为 $50.00 \%$ 和 $23.01 \%$. 自然条件下, 随着温度的上升, 氨氮和总氮的降解系数逐渐增大, 总磷的降解系数逐渐减小.
\end{abstract}

关键词: 自净能力; 温度; 污染物浓度; 流速; 曝气; 渗滤作用; 降解系数; 吸附和释放速率;氨氮; 总磷

\section{Different factors on nitrogen and phosphorus self-purification ability from an urban Guan- du-Huayuan river}

\author{
WANG Rong, HUANG Tianyin ** \&WU Wei \\ ( School of Environmental Science \& Engineering, Suzhou University of Science and Technology, Suzhou 215009, P.R.China)
}

\begin{abstract}
An urban Guandu-Huayuan river in Suzhou was selected to study the impacts of different factors( contaminant concentration, flow velocity, aeration, filtration, microorganisms and temperature) on nitrogen and phosphorus self-purification ability by indoor and outdoor simulation experiment. The results showed that, with the increase of pollutants concentration, ammonia nitrogen and nitrate nitrogen degradation coefficient increased, and the overall sediment phosphorus adsorption rate increased. Compared with static water, the nitrogen and phosphorus self-purification ability can be enhanced by increased velocity, aeration and filtration. The increment of self-purification parameter was $17.05 \%$ for ammonia nitrogen and $34.85 \%$ for total phosphorus( TP) in the velocity change experiment; $8.35 \%$ for ammonia nitrogen and $59.33 \%$ for TP in the aeration experiment; and $50.00 \%$ for ammonia nitrogen and $23.01 \%$ for TP in the filtration experiment. With the increase of temperature in natural conditions, the ammonia nitrogen and total nitrogen degradation coefficient increased gradually, while TP degradation coefficient reduced.
\end{abstract}

Keywords: Self-purification ability; temperature; contaminant concentration; flow velocity; aeration; filtration; degradation coefficient; release and adsorption; ammonia nitrogen; total phosphorus

城市河道分布于城市人口聚集区,生态系统易受土地开发利用的影响 ${ }^{[1]}$,而且一经破坏难以恢复 ${ }^{[2]}$.随 着城市化的发展, 城市河道被多次开发利用和改造, 生态功能遭到严重破坏 ${ }^{\left[{ }^{[3]}\right.}$, 城市天然水系不断萎缩, 水 质急剧恶化,自净能力下降,氮、磷污染尤为严重,部分河道出现黒臭现象.而且,城市内河底泥中积累了大量 重金属及氮、磷等营养元素,在一定条件下,会向上覆水中释放,对河流造成二次污染 ${ }^{[4]}$.因此,降低水体和底 泥中的氮、磷含量成为水体生态修复的关键. 要实现水体生态修复就要恢复水体的自净能力 ${ }^{[5]}$. 河道水体的 自净是由无数的物理、化学和生物因素的直接和间接作用所产生的复杂过程 ${ }^{[6]}$, 是通过一系列自然过程使 氮、磷等污染物质得以转化、吸收、再分配 (底泥的释放与吸附), 并让水体得以净化并能恢复到初始状态的

* 住房和城乡建设部 2014 年科学技术项目 (2014-K5-043) 资助. 2014-10- 17 收稿; 2015-04-28 收修改稿. 王蓉 (1988 ) ,女,硕士研究生;E-mail:maggie1508@126.com.

** 通信作者;E-mail:huangtianyin111@ sohu.com. 
能力 ${ }^{[7-8]}$. 影响水体氮、磷自净能力的因素很多, 如季节性变化 (温度 ${ }^{[9]}$ 、水动力条件 ${ }^{[10]}$ 、溶解氧、微生物、护 岸结构 ${ }^{[11]}$ 、堤坝工程 ${ }^{[12]}$ 等.研究表明, 水体中氮、磷等营养盐的去除率随季节变化很大 ${ }^{[13-14]}$, 温度和溶解氧 能影响底泥中氮、磷等营养盐的释放速率 ${ }^{[15-17]}$, 曝气能影响水体氮、磷去除效果 ${ }^{[18-19]}$; 微生物在一定条件下 能去除水体中的氮、磷 ${ }^{[20-21]}$. 近年来, 对于湖泊、海湾水体 ${ }^{[22-23]}$ 自净能力的研究很多, 基本上只是考虑一个因 素, 而对城市内河自净能力, 尤其是多个影响因素下的变化却鲜有报道. 而且, 一般的研究基本上是在实验室 内进行的, 未考虑自然环境的影响, 与真实情况存在一定差异.

本文综合考虑室内与室外条件, 能较好地反映河道水体的真实情况. 苏州城区河道狭窄, 水流缓慢, 加上 分布于城市人口聚集区, 水体自净能力下降, 氮、磷污染尤为严重. 本研究以典型城市河道 (官渎花园内河) 为研究对象, 通过室内及室外模拟实验, 研究不同污染物浓度、流速、曝气复氧、渗滤作用以及季节温度对河 道水体氮、磷自净能力的影响, 为河道水体生态修复提供依据.

\section{1 研究区域}

官渎花园内河西段位于苏州市 $\left(30^{\circ} 46^{\prime} \sim 32^{\circ} 02^{\prime} \mathrm{N}, 120^{\circ} 11^{\prime} \sim 120^{\circ} 16^{\prime} \mathrm{E}\right)$ 姑苏区, 东端被截断, 形成断头 浜, 水体滞流造成自净能力下降. 该河道位于人口密集区, 污染物来源复杂而分散, 水体污染严重.水体常年 呈墨绿色, 部分河段呈灰黑色, 河面有较多漂浮物, 河水腥臭难闻, 是具有代表性的苏州城区典型的半封闭 型的重污染河道. 由于上游源头申家坟里浜的生活污染物直接汇人, 小型作坊处工业污染物直接人河, 污染 由东向西逐渐减轻.故选择如图 1 所示的 3 个断面研究水体和底泥的氮、磷自净能力.
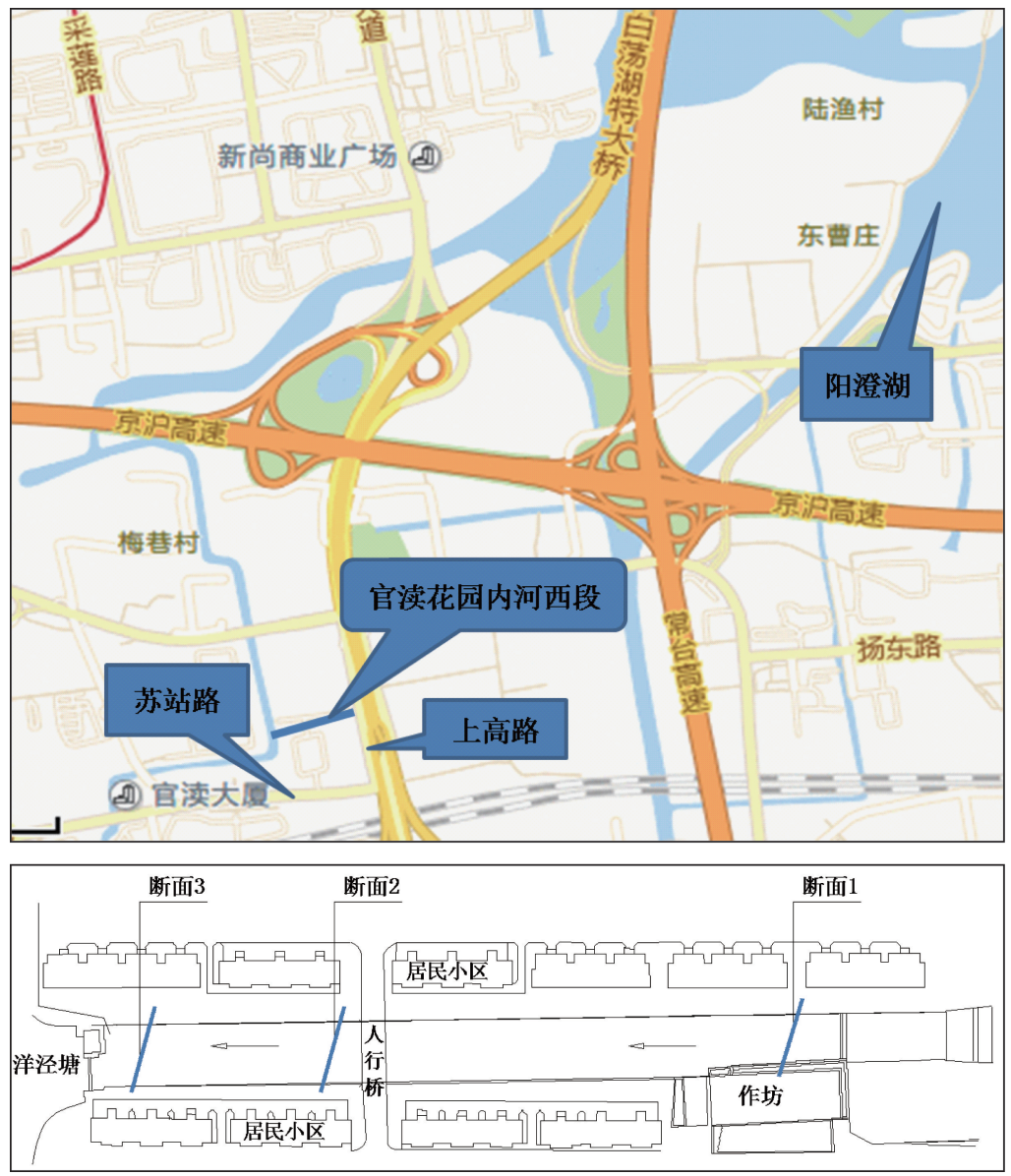

图 1 研究区域及采样断面位置

Fig.1 Location of the study area and the sampling profiles 


\section{2 实验内容与方法}

\section{1 实验原理}

水体氮、磷的自净能力主要体现在水体中氮、磷的转化及底泥中磷的吸附与释放效应. 因此用氨氮 $\left(\mathrm{NH}_{3}-\mathrm{N}\right)$ 降解系数、硝态氮 $\left(\mathrm{NO}_{3}^{-}-\mathrm{N}\right)$ 降解系数、总氮 $(\mathrm{TN})$ 降解系数、总磷 $(\mathrm{TP})$ 降解系数、底泥磷的吸附和释 放速率等自净参数来表征水体氮、磷的自净能力. 研究 ${ }^{[24-25]}$ 表明, 对于中小型河流, 河流流速较小, 且在水体 污染物浓度较低时, 水体中污染物的降解符合一级反应动力学, 即:

$$
\ln C_{0}=\ln C_{t}+K \cdot t
$$

式中, $C_{0}$ 为初始浓度, $C_{t}$ 为第 $t$ 天的浓度, $t$ 为时间, $K$ 值即为相应的污染物降解系数.

\section{2 实验材料}

取 3 个断面处上覆水样和底泥. 水样用聚乙烯瓶储存, 按照文献 [ 26] 中的分析方法, 测定 $\mathrm{TN} 、 \mathrm{NH}_{3}-\mathrm{N} 、$ $\mathrm{NO}_{3}^{-}-\mathrm{N} 、 \mathrm{TP}$ 、溶解性磷酸盐 ( SRP) 等理化指标浓度. 底泥是由柱状采样器采集的无扰动柱状样 (表层 $0 \sim$ $10 \mathrm{~cm})$, 于 $4^{\circ} \mathrm{C}$ 下保存, 测定氮、磷含量等理化指标: TP 含量采用碱性过硫酸钾氧化法测定, $\mathrm{NH}_{3}-\mathrm{N}$ 含量采用 氯化钾提取法测定, 底泥中的有效磷( Olsen-P) 含量采用碳酸氢钠提取法 ${ }^{[27]}$ 测定.

\section{3 实验内容}

通过室内模拟实验确定污染物浓度对氮、磷自净的影响; 然后通过室外模拟实验确定水动力条件、曝气 复氧、渗滤作用及温度对氮、磷自净的影响.

2.3.1 室内模拟实验 (1) 水体 $\mathrm{NH}_{3}-\mathrm{N}$ 和 $\mathrm{NO}_{3}^{-}-\mathrm{N}$ 降解系数的测定: 取 3 个断面的水样 $100 \mathrm{ml}$, 用硫酸铵将 $\mathrm{NH}_{3}-\mathrm{N}$ 浓度调至 $200 \mathrm{mg} / \mathrm{L}$ 左右, $5 \mathrm{~d}$ 内每天测定溶液中 $\mathrm{NH}_{3}-\mathrm{N}$ 浓度; 取 3 个断面的水样 $100 \mathrm{ml}$, 用硝酸钾将 $\mathrm{NO}_{3}^{-}-\mathrm{N}$ 浓度调至 $10 \mathrm{mg} / \mathrm{L}$ 左右, $5 \mathrm{~d}$ 内每天测定溶液中 $\mathrm{NO}_{3}^{-}-\mathrm{N}$ 浓度.

(2) 底泥磷吸附速率及释放速率 ${ }^{[28]}$ 的测定.

吸附速率的测定: 分别取 3 个监测断面的上覆水样, 测定其 SRP 浓度. 分别在 $250 \mathrm{ml}$ 的雉形瓶中加人新 鲜底泥样品 $5 \mathrm{~g}$, 再小心注人 $100 \mathrm{ml}$ 吸附水样( 由磷酸二氢钾及上覆水水样配制而成, $\mathrm{SRP}$ 浓度在 $1.5 \mathrm{mg} / \mathrm{L}$ 左右), 避免底泥扰动.分别在 $3 、 6 、 9 、 12 、 24 、 36 、 48 \mathrm{~h}$ 时测定水中 SRP 浓度,测定后扰动上覆水.

释放速率的测定: 分别取 3 个监测断面的上覆水样, 测定水中 SRP 浓度. 分别在 $250 \mathrm{ml}$ 的雉形瓶中加人 新鲜底泥样品 $5 \mathrm{~g}$, 再小心注人 $100 \mathrm{ml}$ 上覆水样品, 避免底泥扰动, 于室温条件下敞口蔽光培养. 分别在 $3 、 6$ 、 $9 、 12 、 24 、 36 、 48 \mathrm{~h}$ 时测定水中 SRP 浓度, 测定后扰动上覆水.

2.3.2 室外模拟实验 以官渎花园内河 (天然河道长 $180 \mathrm{~m}$, 宽 $18 \mathrm{~m}$, 水深 $1.5 \mathrm{~m}$ ) 为原型, 建立模拟河道, 研究官 渎花园内河在无外源污染且水体滞流的状态下水质的变化情况. 结合试验场地等多种因素, 确定模拟河道的纵 横向比例尺 $\lambda_{\mathrm{L}}=30$, 垂直方向比例尺 $\lambda_{\mathrm{h}}=5$, 确定模拟河道的长为 $6.0 \mathrm{~m}$, 宽为 $0.6 \mathrm{~m}$, 水深为 $0.3 \mathrm{~m}$ (图 2). 模拟 河道由水泥砂浆砌成, 由进水区、出水区 (都为 $0.3 \mathrm{~m}$ ) 和河道主体组成, 过水断面为矩形, 在进、出水区与河道 主体的连接端设有 $0.15 \mathrm{~m}$ 高的挡泥槛. 底部铺有 $0.1 \mathrm{~m}$ 高的底泥, 河水层高度为 $0.3 \mathrm{~m}$. 实验中的底泥和用水均取 自官渎内河断面 1 . 模拟河道分为两组:一组为对照组,不做任何处理; 另一组为实验组,分别在以下条件下运行:

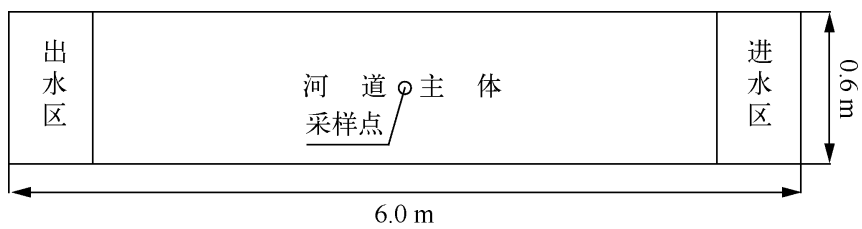

图 2 模拟河道

Fig.2 Simulant water course

(1) 流速: 用水葲和转子流量计将流速调为 $16 \mathrm{~m} / \mathrm{h}$ (按生态流速和不淤积流速所取); (2) 曝气复氧: 通 过外部气泵向位于实验模拟河道中央的曝气头输送空气来进行复氧, 使 DO 浓度在 $6 \sim 8 \mathrm{mg} / \mathrm{L}$; (3) 渗滤装 
置: 通过外部计量洜和渗滤装置增加微生物种类和数量. 渗滤装置由圆柱型的有机玻璃管制成, 其中半径 $0.5 \mathrm{~m}$, 高 $1.8 \mathrm{~m}$. 实验水流由装置底部进人, 由上部排出. 装置由集水层 $(0.2 \mathrm{~m}$, 位于装置底部)、承托层 $(0.3 \mathrm{~m}$, 由 3 个级配 $(50 \mathrm{~mm} 、 30 \mathrm{~mm} 、 10 \mathrm{~mm})$ 的我鸟卵石构成) 和滤料层 $(0.5 \mathrm{~m}$, 采用半径为 $5 \mathrm{~mm}$ 的陶粒) 组 成,穿孔板位于集水层和承托层之间, 使布水均匀. 渗滤净化装置流量 $Q=0.36 \mathrm{~m}^{3} / \mathrm{d}$, 水力负荷 $q=0.458$ $\mathrm{m}^{3} /\left(\mathrm{m}^{2} \cdot \mathrm{d}\right)$, 计量泵流量为 $30 \mathrm{~L} / \mathrm{h}$.

实验在 3 个季节内 (夏、秋、冬季平均温度分别为 $30.23 、 20.27 、 9.47^{\circ} \mathrm{C}$ ) 进行, 不做任何处理的河道水质 的变化即为温度的影响实验. 每种条件运行 $24 \mathrm{~d}$, 于采样点每隔 $4 \mathrm{~d}$ 采集 1 次水样, 测定水体 $\mathrm{pH}$ 值、浊度和 $\mathrm{DO} 、 \mathrm{TP} 、 \mathrm{NH}_{3}-\mathrm{N} 、 \mathrm{TN}$ 及 $\mathrm{NO}_{3}^{-}-\mathrm{N}$ 浓度.

\section{3 结果与讨论}

\section{1 污染物浓度对氮、磷自净的影响}

表 1 底泥及上覆水的理化性质

Tab.1 Physical and chemical properties of sediment and overlying water

\begin{tabular}{|c|c|c|c|c|}
\hline & \multirow{2}{*}{ 指标 } & \multicolumn{3}{|c|}{ 采样断面 } \\
\hline & & 1 & 2 & 3 \\
\hline \multirow[t]{5}{*}{ 底泥 } & $\mathrm{TP} /(\mathrm{mg} / \mathrm{kg})$ & 743.75 & 668.75 & 512.50 \\
\hline & Olsen-P/( $\mathrm{mg} / \mathrm{kg})$ & 80.40 & 76.40 & 39.20 \\
\hline & $\mathrm{NH}_{3}-\mathrm{N} /(\mathrm{mg} / \mathrm{kg})$ & 405.00 & 179.88 & 124.63 \\
\hline & 含水率/\% & 46.57 & 46.55 & 34.56 \\
\hline & 有机质/\% & 3.01 & 2.27 & 2.06 \\
\hline \multirow[t]{6}{*}{ 上覆水 } & $\mathrm{TP} /(\mathrm{mg} / \mathrm{L})$ & 1.59 & 1.29 & 1.23 \\
\hline & $\mathrm{SRP} /(\mathrm{mg} / \mathrm{L})$ & 1.24 & 1.07 & 0.96 \\
\hline & $\mathrm{NH}_{3}-\mathrm{N} /(\mathrm{mg} / \mathrm{L})$ & 17.95 & 15.58 & 15.47 \\
\hline & $\mathrm{TN} /(\mathrm{mg} / \mathrm{L})$ & 22.60 & 19.69 & 19.29 \\
\hline & $\mathrm{NO}_{3}^{-}-\mathrm{N} /(\mathrm{mg} / \mathrm{L})$ & 0.33 & 0.39 & 0.42 \\
\hline & $\mathrm{DO} /(\mathrm{mg} / \mathrm{L})$ & 0.12 & 0.15 & 3.80 \\
\hline
\end{tabular}

从表 1 可以看出,断面 $1 、 2 、 3$ 底泥中各项指标 均呈现递减趋势, 即污染逐渐减轻. TP 含量明显偏 高, 是水体中的 500 倍以上; $\mathrm{NH}_{3}-\mathrm{N}$ 含量相对较小, 是水体中的 10 倍以上, 底泥是氮、磷的汇. Olsen-P 可用于表征生物可利用的磷 ${ }^{[29]}$, 在 3 个断面上分别 占底泥 TP 的 $7.65 \% 、 11.42 \%$ 和 $10.81 \%$. 根据英国农 业发展和咨询服务指标体系, 当土壤中 Olsen-P 含 量超过 $46 \mathrm{mg} / \mathrm{kg}$ 时处于富营养状态 ${ }^{[27]}$, 表明断面 1 和 2 明显处于富营养状态. 底泥含水率与有机质含 量与太湖月亮湾的基本相同 ${ }^{[30]}$, 有机质可以和元素 $\mathrm{Ca} 、 \mathrm{Mg} 、 \mathrm{Fe} 、 \mathrm{Al}$ 等形成配合物, 潜在影响水体中磷的转 化. 3 个断面水体 TN 浓度为 $9.53 \sim 31.89 \mathrm{mg} / \mathrm{L}, \mathrm{NH}_{3}-\mathrm{N}$ 浓度为 $7.43 \sim 24.35 \mathrm{mg} / \mathrm{L}$, 氮素污染严重, $\mathrm{NH}_{3}-\mathrm{N}$ 是 河流中氮素循环的主要形态, 其浓度约占 TN 浓度 的 $80 \%$. 水体 $\mathrm{TP}$ 浓度为 $1.19 \sim 2.86 \mathrm{mg} / \mathrm{L}, \mathrm{SRP}$ 浓度 为 $0.99 \sim 2.61 \mathrm{mg} / \mathrm{L}$, 远远超过国家地表水环境质量 标准中 $V$ 类水标准 $(0.40 \mathrm{mg} / \mathrm{L})$.

3.1.1 污染物浓度对氮自净的影响 随着污染物浓度的减小, 3 个断面的 $\mathrm{NH}_{3}-\mathrm{N}$ 降解系数和 $\mathrm{NO}_{3}^{-}-\mathrm{N}$ 降解系 数逐渐减小, 相应氮素的降解减慢 (图 3). 另外, $\mathrm{NO}_{3}^{-}-\mathrm{N}$ 的降解系数为负值, $\mathrm{NO}_{3}^{-}-\mathrm{N}$ 含量随断面呈上升趋势. $\mathrm{NO}_{3}^{-}-\mathrm{N}$ 降解系数明显小于 $\mathrm{NH}_{3}-\mathrm{N}$ 降解系数, 说明水体的硝化作用增强, 反硝化作用受到抑制. 反硝化作用发 生的 3 个条件为: 具备有效硝酸盐或亚硝酸盐、低氧浓度和电子供体 ${ }^{[31]}$. 但主要的限制条件为: 满足产生硝 酸盐所需要的高 DO 浓度和反硝化作用所需要的低 DO 浓度 $(<0.2 \mathrm{mg} / \mathrm{L})$, 故反硝化作用只发生在好氧 $/$ 缺 氧界面上,而且这个界面必须是时间上或(和)空间上相分离的 ${ }^{[32]}$, 因此 DO 成为水体脱氮的限制因素. 断面 3 处 DO 浓度为 $3.8 \mathrm{mg} / \mathrm{L}$, 所以反硝化作用受抑制. 断面 1 和 2 的 DO 浓度均小于 $0.2 \mathrm{mg} / \mathrm{L}$, 适合发生反硝化作 用, 然而反硝化作用却受到抑制, 原因为: 断面 1 和 2 有低 DO 浓度和丰富的电子供体, 虽然有利于反硝化作 用, 却限制了亚硝化细菌和硝化细菌的作用, 长期低浓度 $(<0.2 \mathrm{mg} / \mathrm{L})$ 的硝酸盐使反硝化作用缺乏底物, 降 低了反硝化作用的效率, 最终导致氮素只能停留在 $\mathrm{NH}_{3}-\mathrm{N}$ 形态.

3.1.2 污染物浓度对磷自净的影响 3 个断面不同底泥中磷的吸附和释放规律如图 4 所示. 底泥磷吸附速率 和释放速率的计算公式为:

$$
K=\frac{\left[\left(C_{n}-C_{0}\right) \cdot V+\sum_{i=1}^{n} V_{j}\left(C_{i-1}-C_{\mathrm{a}}\right)\right]}{w \cdot t}
$$

式中, $V$ 为上覆水体积, $C_{n} 、 C_{0}$ 和 $C_{i-1}$ 分别为第 $n$ 次、初始和第 $(i-1)$ 次采样时的 SRP 浓度, $C_{\mathrm{a}}$ 为添加水样中 

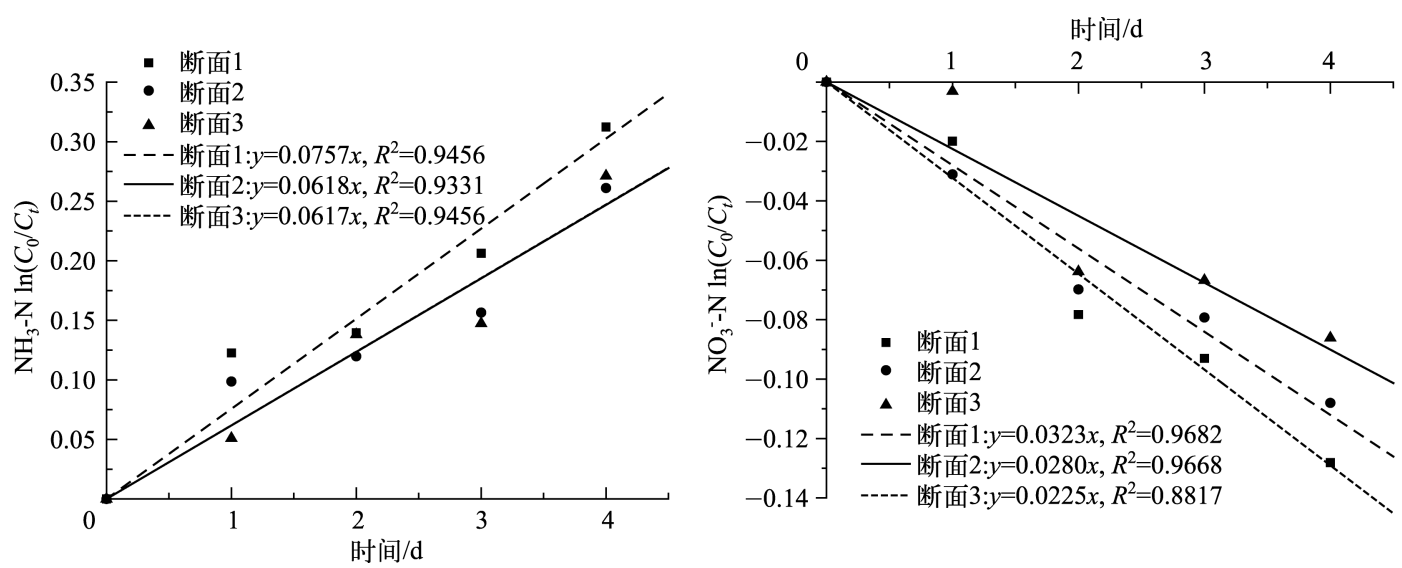

图 3 氨氮和硝态氮降解系数

Fig.3 Ammonia nitrogen and nitrate nitrogen degradation coefficient

的 SRP 浓度, $V_{j}$ 为每次的采样体积, $w$ 为底泥的湿重, $t$ 为吸附和释放时间.

由吸附实验可以看出, 断面 1 在第 $2 \mathrm{~h}$,断面 2 和 3 在第 $3 \mathrm{~h}$ 的 SRP 浓度达到最大值, 分别为 $1.42 、 1.99$ 和 $2.02 \mathrm{mg} / \mathrm{L}$, 明显高于初始值, 可能是由上覆水的扰动造成的, 扰动打破了底泥与水界面间的动态平衡, 使 SRP 得以释放. 随后急剧下降, 底泥对 SRP 的吸附占主导, 在第 $8 \mathrm{~h}$ 后趋于稳定 (图 4). 3 个断面对磷的吸附 量随着污染的减轻而逐渐增加 (表 2). 即随着污染物浓度的升高, 底泥对磷的吸附能力减弱 ${ }^{[33]}$.

由释放实验可知, 断面 2 和 3 在第 $3 \mathrm{~h} \mathrm{SRP}$ 浓度达到最大值, 而断面 1 一直呈下降趋势, $24 \mathrm{~h}$ 后 3 个断 面的 SRP 浓度基本趋于稳定 (图 4). 断面 2 和 3 在前 $3 \mathrm{~h}$ 底泥中的磷有明显释放,水中 SRP 浓度高于初始 值,之后底泥中磷的吸附占主导. 断面 1 在初始时刻, SRP 浓度最大, 释放却受抑制, 即上覆水中 SRP 的初始 浓度越大, 对底泥释放磷的抑制作用越大 ${ }^{[34]}$.
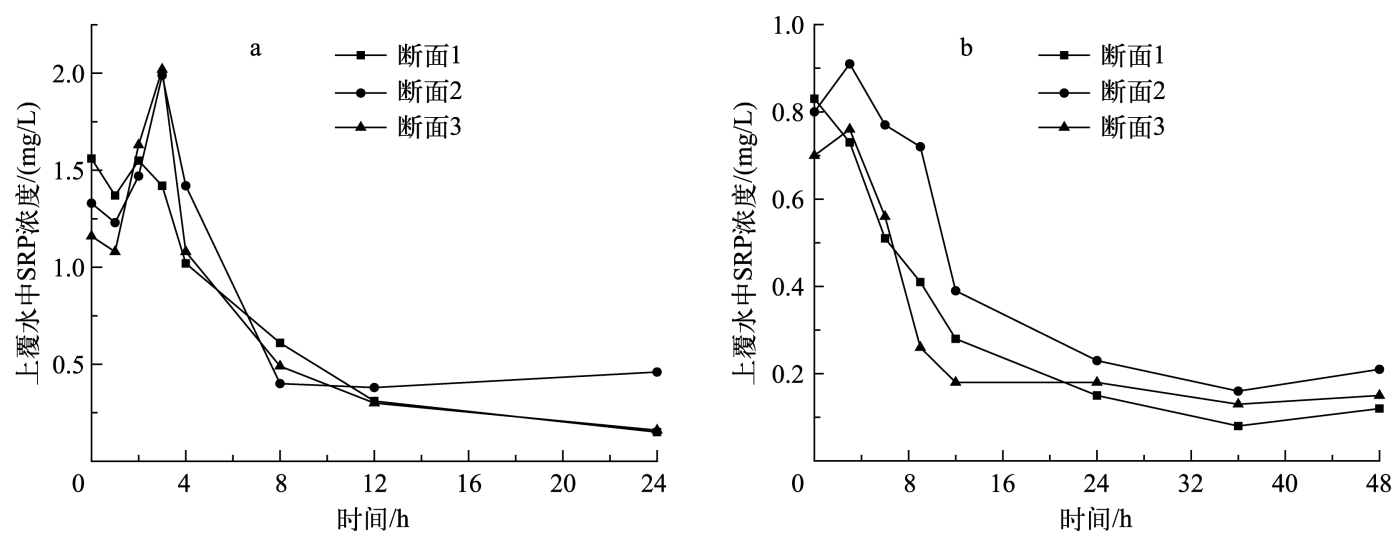

图 4 底泥磷的吸附 (a) 和释放 (b) 规律

Fig.4 Laws of sediment phosphorus adsorption( a ) and release( b)

表 2 不同断面底泥中磷的吸附与释放速率

Tab.2 Sediment phosphorus adsorption and release rates of different sections

\begin{tabular}{cccc}
\hline 断面 & 吸附速率 $V /(\mathrm{mg} /(\mathrm{g} \cdot \mathrm{d}))$ & 释放速率 $v /(\mathrm{mg} /(\mathrm{g} \cdot \mathrm{d}))$ & 总体吸附速率 $/(\mathrm{mg} /(\mathrm{g} \cdot \mathrm{d}))$ \\
\hline 1 & 0.0210 & 0.0029 & 0.0182 \\
2 & 0.0235 & 0.0031 & 0.0204 \\
3 & 0.0244 & 0.0026 & 0.0218 \\
\hline
\end{tabular}


由表 1 和表 2 可知, 底泥中磷以吸附为主, 吸附速率是释放速率的 10 倍左右; 底泥是磷的蓄积库, 磷的 污染主要是水体的污染. 吸附速率为断面 $3>$ 断面 $2>$ 断面 1 , 释放速率为断面 $2>$ 断面 $1>$ 断面 3 . 定义底泥中磷 的总体吸附速率为吸附速率和释放速率之差, 总体吸附速率的大小可反映断面底泥中磷的自净能力, 其值 越大, 证明磷的自净速率越快. 由表 2 可知, 3 个断面底泥磷的自净速率为断面 $3>$ 断面 $2>$ 断面 1 , 即随着污染 物浓度的减小, 底泥对磷的自净速率加快.

\section{2 流速对氮、磷自净的影响}

与静止水体相比, 水体流速变为 $16 \mathrm{~m} / \mathrm{h}$ 后, $\mathrm{NH}_{3}-\mathrm{N}$ 降解系数和 $\mathrm{TP}$ 降解系数都增大, 增幅分别为 $17.05 \%$ 和 34.85\% ( 图 5). 整个实验期间, 实验河道浊度都要高于参照河道.

在实验前 $20 \mathrm{~d}$, 参照河道的 $\mathrm{NH}_{3}-\mathrm{N}$ 降解都比实验河道的要快, 可能是由于水体扰动使部分底泥上浮, 造 成含氮污染物的释放所致. 水体扰动使悬浮颗粒物的絮凝沉淀速率加快, 而颗粒物能对 $\mathrm{NH}_{3}-\mathrm{N}$ 进行吸附, 颗 粒物越多, $\mathrm{NH}_{3}-\mathrm{N}$ 降解速率越快 ${ }^{[35]}$, 使后期 $\mathrm{NH}_{3}-\mathrm{N}$ 得以去除.

对于 TP 的降解, 改变流速加快氧气向水体底部传输的速率, 增加泥水界面的氧化氛围, 使底部微生物 吸附降解磷的速率加快.
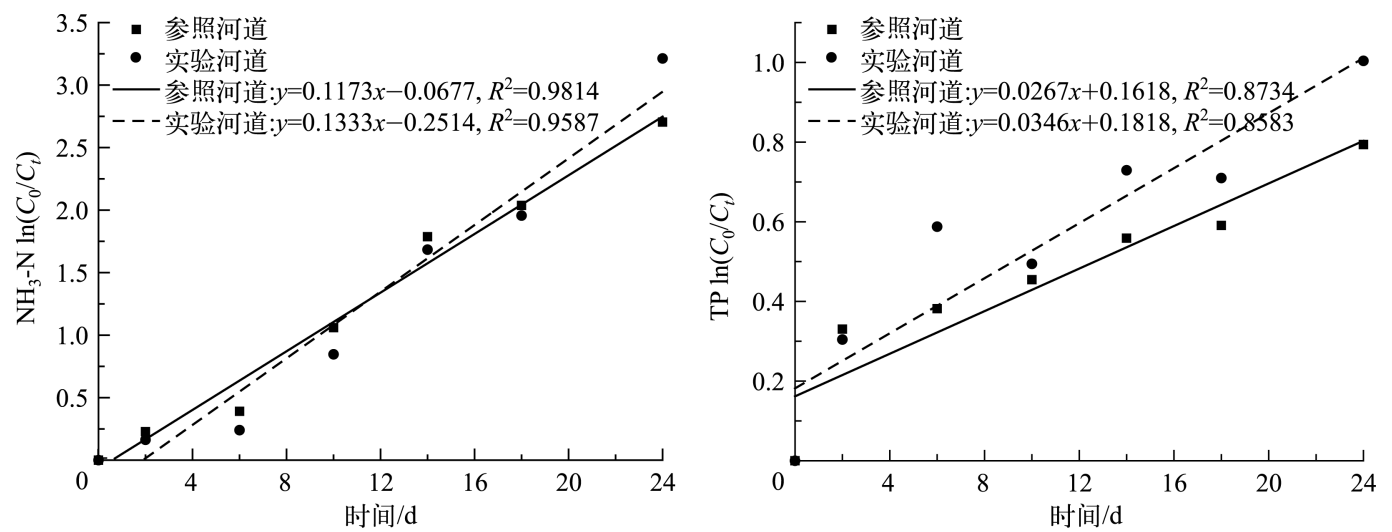

图 5 水动力条件对氮、磷降解的影响

Fig.5 The influence of hydrodynamic conditions on nitrogen and phosphorus degradation

\section{3 曝气复氧对氮、磷自净的影响}

曝气复氧使实验河道 DO 浓度维持在 $6 \sim 8 \mathrm{mg} / \mathrm{L}$, 参照河道 DO 浓度一直处于 $1.2 \mathrm{mg} / \mathrm{L}$ 左右. 曝气复氧使 $\mathrm{NH}_{3}-\mathrm{N}$ 和 TP 降解都加快,对 $\mathrm{NH}_{3}-\mathrm{N}$ 降解的增幅不明显,仅为 8.35\% ; TP 降解显著增强,增幅为 59.33\% (图 6).
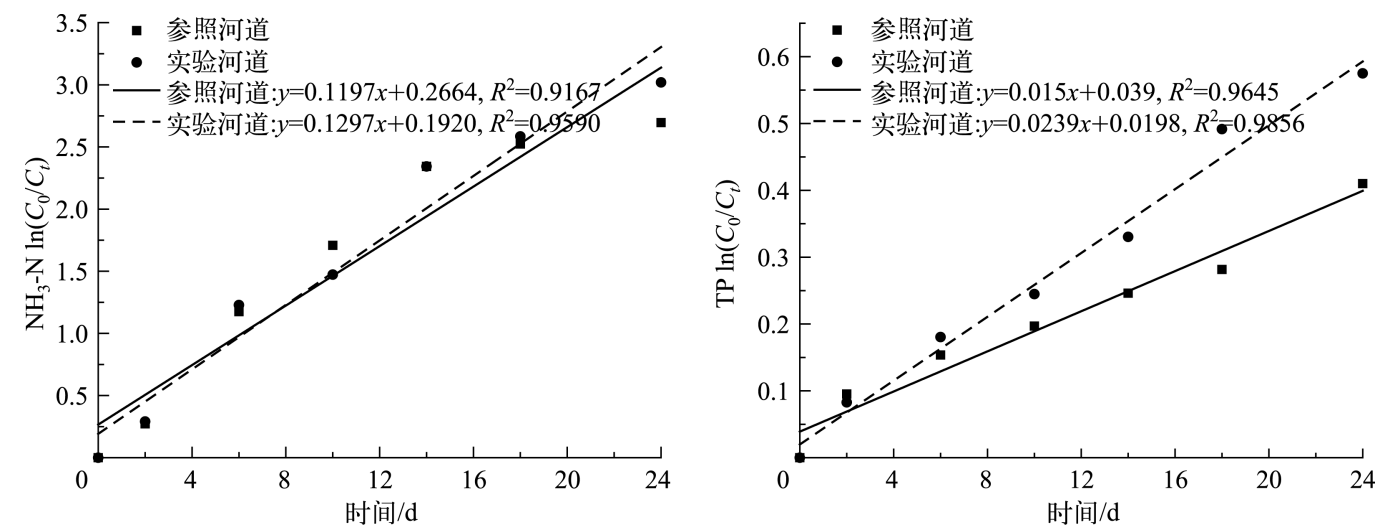

图 6 曝气复氧对氮、磷降解的影响

Fig. 6 The influence of aeration on nitrogen and phosphorus degradation 
曝气充氧一方面增强了水体扰动, 使污染物从底泥中释放到水体, 故开始时 $\mathrm{NH}_{3}-\mathrm{N}$ 降解比参照河道慢; 另一方面, 曝气增加了水中的 $\mathrm{DO}$ 浓度, 使水体 $\mathrm{pH}$ 值维持在 8 左右, 氨氧化速率加快 ${ }^{[36]}$, 后期 $\mathrm{NH}_{3}-\mathrm{N}$ 降解 加快.

天然河道中磷的去除主要是靠物理除磷 (卵石的吸附作用) 和生物除磷 (悬浮生长的细胞和植物直接吸 收磷和底泥中的聚磷微生物好氧过量吸收磷), 其中, 聚磷微生物的好氧过量吸磷是去除磷的主要途

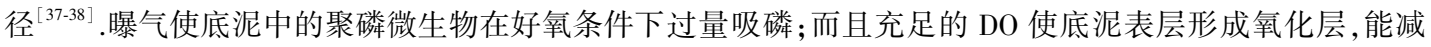
缓底泥中磷的释放, 也能对上覆水中的 $\mathrm{PO}_{4}^{3-}$ 进行专属性吸附. 故 TP 降解系数显著提高.

\section{4 渗滤装置对氮、磷自净的影响}

渗滤装置形成生物膜, 微生物种类和数量增多, 两组河道的 DO 浓度都维持在 $1.5 \mathrm{mg} / \mathrm{L}$ 以上.渗滤装置 提高了 $\mathrm{NH}_{3}-\mathrm{N}$ 和 TP 的降解速率, 其中 $\mathrm{NH}_{3}-\mathrm{N}$ 增量达 $50.00 \%$; TP 的增幅为 $23.01 \%$ (图 7).
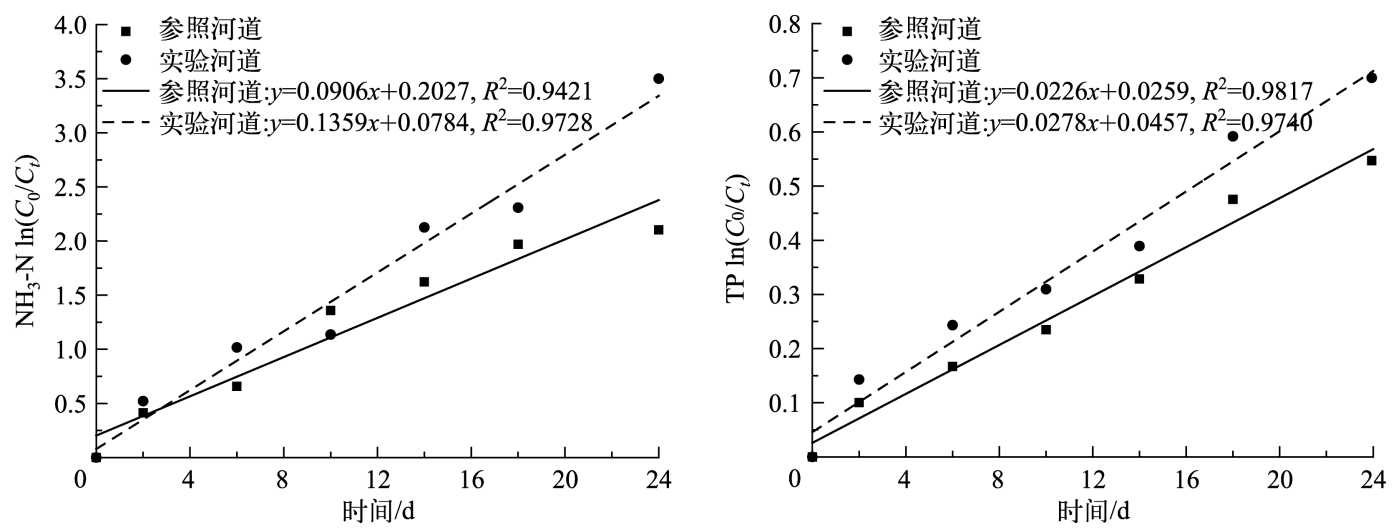

图 7 渗滤装置对氮、磷降解的影响

Fig.7 The influence of filtration on nitrogen and phosphorus degradation

水中 $\mathrm{NH}_{3}-\mathrm{N}$ 的去除通过分子扩散作用、微生物的吸附作用、硝化或氨氧化过程进行 ${ }^{[18]}$, 其中硝化或氨 氧化过程是去除 $\mathrm{NH}_{3}-\mathrm{N}$ 的主要途径. 渗滤装置中形成的生物膜由于固着在陶粒滤料上, 因此世代时间较长 的细菌如亚硝酸盐细菌、氨氧化细菌等硝化细菌能在其中较好地生长 ${ }^{[39]}$. 而且, 水体中 DO 浓度在 $1.5 \mathrm{mg} / \mathrm{L}$ 以上, 呈偏碱性, 较利于硝化作用的发生. 首先, 通过滤料上带负电的微生物对 $\mathrm{NH}_{3}-\mathrm{N}$ 起吸附作用, 接下来通过硝化作用将 $\mathrm{NH}_{3}-\mathrm{N}$ 转化为 $\mathrm{NO}_{3}^{-}-\mathrm{N}^{[40]}$, 进一步对 $\mathrm{NH}_{3}-\mathrm{N}$ 进行吸附, 使其降解速率明显提高.

水流通过渗滤装置时, 使磷与填料充分接触, 提高了聚磷微生物对磷的吸附去除性能; 而且渗滤装置中 存在的大量微生物, 也能通过生命活动消耗部分磷, 填料中的鹅卵石也能吸附去除部分磷 ${ }^{[38]}$.

\section{5 温度对氮、磷自净的影响}

在 3 个季节内, 水体中氮、磷自然降解, 其降解变化如图 8 所示. 自然条件下, 随着温度的升高, $\mathrm{NH}_{3}-\mathrm{N}$ 和 $\mathrm{TN}$ 降解系数逐渐升高, 在夏季 (平均水温为 $30.23^{\circ} \mathrm{C}$ ) 时达到最大. 对于 $\mathrm{NH}_{3}-\mathrm{N}$ 降解, 温度每升高 $10^{\circ} \mathrm{C}, \mathrm{NH}_{3}-\mathrm{N}$ 降解系数的增量为 $2.05 \% \sim 268.86 \%$; 在 $20.23^{\circ} \mathrm{C}$ 时是 $9.47^{\circ} \mathrm{C}$ 时的 4 倍左右, 而 $30.23^{\circ} \mathrm{C}$ 时和 $20.27^{\circ} \mathrm{C}$ 时相差不 大. 对于 TN 降解, 温度每升高 $10^{\circ} \mathrm{C}$, TN 降解系数的增量为 $85.85 \% \sim 92.88 \%$. 水体中 TN 的去除过程主要包括 氨化、硝化和反硝化作用以及微生物的生长对各类氮源的利用, 其中 $\mathrm{NH}_{3}-\mathrm{N}$ 的去除主要是通过硝化作用和 氨氧化作用. 整个实验期间, 随着水温的升高, 水体中生物体和微生物的活性增强, 促进了底泥中含氮有机物 的矿化作用,硝化速率显著增强 ${ }^{[41]}, \mathrm{NH}_{3}-\mathrm{N}$ 迅速降解; 反硝化作用也增强, $\mathrm{TN}$ 也得以迅速去除.

随着温度的升高, TP 降解系数逐渐变小, 且温度每升高 $10^{\circ} \mathrm{C}$ 则 TP 降解系数减少 $32.40 \% \sim 43.82 \%$.水中 的磷包括溶解态磷和颗粒态磷, 磷在水体中的转化主要有沉淀作用和底泥的释磷作用. 大部分颗粒态磷沉人 水体与钙、铝、铁等金属离子形成不溶性磷.温度升高加速了磷的矿化作用, 使不溶性磷酸盐的溶解度增大, 使底泥中的有机结合态磷释放到水体; 此时微生物的活性增强, 降低了底泥表面的氧化还原电位, 可能会促 进铁结合态磷的释放 ${ }^{[42]}$. 此时, 水体中 $\mathrm{pH}$ 值达到 8 以上, 磷主要以 $\mathrm{H}_{2} \mathrm{PO}_{4}^{-}$形式存在, 有利于磷酸根离子从氢 

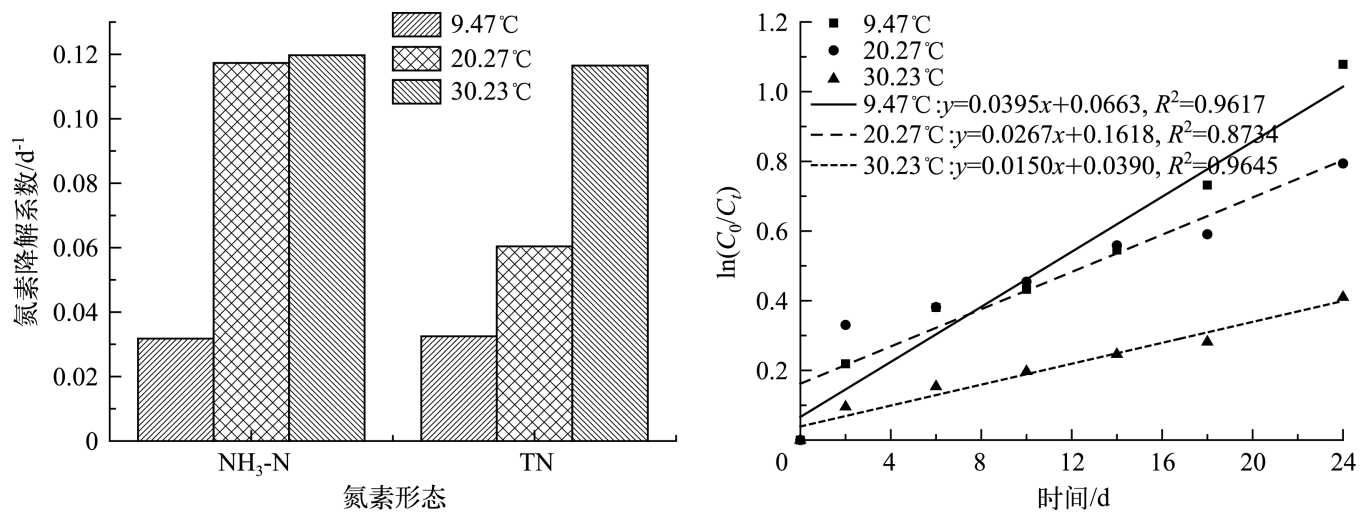

图 8 温度对氮、磷降解的影响

Fig. 8 The influence of temperature on nitrogen and phosphorus degradation

氧化铁胶体中分解吸附, 沉淀作用减弱, 使更多的磷酸盐得以释放到水体 ${ }^{[43]}$, 故 TP 降解速率减慢.

\section{4 结论}

通过室内和室外模拟实验, 得出的主要结论如下:

1) 室内模拟实验显示: 随着污染物浓度的增大, $\mathrm{NH}_{3}-\mathrm{N}$ 降解系数和 $\mathrm{NO}_{3}^{-}-\mathrm{N}$ 降解系数逐渐增大, 但是 $\mathrm{NH}_{3}-\mathrm{N}$ 降解系数要远远大于 $\mathrm{NO}_{3}^{-}-\mathrm{N}$ 降解系数, 反硝化受抑制, 水体氮素只能停留在 $\mathrm{NH}_{3}-\mathrm{N}$ 形态. 底泥磷的总 体吸附速率随着污染物浓度的增大而减小, 以吸附为主, 吸附速率是释放速率的 10 倍左右.

2) 室外模拟实验显示: 与静止水体相比, 模拟河道通过改变流速、曝气复氧和渗滤作用, 能增强水体氮、 磷的自净能力, 提高氮、磷降解速率. 其中, 渗滤能显著提高 $\mathrm{NH}_{3}-\mathrm{N}$ 降解系数, 曝气复氧能显著提高 $\mathrm{TP}$ 降解 系数.

3) 在自然条件下,随着水体温度的升高, $\mathrm{NH}_{3}-\mathrm{N}$ 和 $\mathrm{TN}$ 降解系数逐渐增大, $\mathrm{TP}$ 降解系数则逐渐减小.

影响水体的氮、磷自净能力的因素包括污染物浓度、温度、DO 浓度、水流要素、渗滤作用等.要达到水体 氮、磷生态修复的目的, 可以考虑将渗滤和曝气复氧相结合, 提高氮、磷去除效果.

\section{5 参考文献}

[ 1 ] Walsh CJ, Roy AH, Feminella JW et al. The urban stream syndrome: Current knowledge and the search for a cure. Journal of the North American Benthological Society, 2005, 24(3) : 706-723.

[ 2 ] Houser JN, Richardson WB. Nitrogen and phosphorus in the upper mississippi river: Transport, processing, and effects on the river ecosystem. Hydrobiologia, 2010, 640(1): 71-88.

[ 3 ] Sala OE, Chapin FS, Armesto JJ et al. Global biodiversity scenarios for the year 2100. Science, 2000, 287 ( 5459 ): 1770-1774.

[ 4 ] 贾晓珊, 徐昕荣, 李适宇等. 珠江流域河网底泥的氮磷污染特征及释放机理. 中山大学学报: 自然科学版, 2005, 44(2): 107-110.

[ 5 ] Ostroumov SA. On some issues of maintaining water quality and self-purification. Water Resources, 2005, 32(3) : 337-346.

[ 6 ] Roberta V, Paola M, Mario F et al. Self-purification ability of a resurgence stream. Chemosphere, 2003, 52 (10): $1781-1795$.

[ 7 ] 韩 涛, 翟淑华, 胡维平等. 太湖氮、磷自净能力的实验与模型模拟. 环境科学, 2013, 34(10): 3862-3871.

[8] Benoit RJ. Self-purification in natural waters. Water and water pollution handbook, 1971: 223-261.

[ 9 ] 许 否, 李 华, 陈英旭等. 南太湖地区小型浅水湖泊自净能力季节变化研究. 环境科学, 2010, 31(4): 924-930.

[10] Heidenwag I, Langheinrich U, Luederitz V. Self-purification in upland and lowland streams. Acta Hydrochimica et Hydrobiologica, 2001, 29(1): 22-33.

[11] 林 桔, 潘伟斌, 曹英姿等. 格宾护岸填料类型对河道自净能力的影响. 环境工程学报, 2012, 6( 5) : 1565-1570.

[12] Wei GL, Yang ZF, Cui BS et al. Impact of dam construction on water quality and water self-purification capacity of the 
lancang river, china. Water Resources Management, 2009, 23(9) : 1763-1780.

[13] Li Z, Guo JS, Long M et al. Seasonal variation of nitrogen and phosphorus in xiaojiang river - a tributary of the three gorges reservoir. Frontiers of Environmental Science \& Engineering in China, 2009, 3(3): 334-340.

[14] Eilola K. On the dynamics of organic nutrients, nitrogen and phosphorus, in the baltic sea. SMHI Reports Oceanography, 2009.

[15] Malecki LM, White JR, Reddy KR. Nitrogen and phosphorus flux rates from sediment in the lower st. Johns river estuary. Journal of Environmental Quality, 2004, 33(4) : 1545-1555.

[16] 袁文权, 张锡辉, 张丽萍. 不同供氧方式对水库底泥氮磷释放的影响. 湖泊科学, 2004, 16(1): 29-35. DOI 10. 18307/2004. 0104.

[17] 范成新, 张 路, 包先明等. 太湖沉积物-水界面生源要素迁移机制及定量化-2. 磷释放的热力学机制及源-汇 转换. 湖泊科学, 2006, 18(3): 207-217. DOI 10. 18307/2006. 0303.

[18］凌 芬, 刘 波, 王国祥等. 曝气充氧对城市污染河道内源铵态氮释放的控制. 湖泊科学, 2013, 25(1): 23-30. DOI 10. 18307/2013. 0104.

[19] 李大鹏, 黄 勇, 李伟光. 底泥曝气改善城市河流水质的研究. 中国给水排水, 2007, 23( 5): 22-25.

[20] Liang Z, Liu Y, Ge F et al. Efficiency assessment and $\mathrm{pH}$ effect in removing nitrogen and phosphorus by algae-bacteria combined system of chlorella vulgaris and bacillus licheniformis. Chemosphere, 2013, 92(10): 1383-1389.

[21] Tsuneda S, Ohno T, Soejima K et al. Simultaneous nitrogen and phosphorus removal using denitrifying phosphate-accumulating organisms in a sequencing batch reactor. Biochemical Engineering Journal, 2006, 27(3) : 191-196.

[22] 任瑞丽, 刘茂松, 章杰明等. 过水性湖泊自净能力的动态变化. 生态学杂志, 2007, 26(8): 1222-1227.

[23] 何本茂, 韦蔓新. 北海湾水体自净能力的探讨. 海洋环境科学, 2004, 23(1): 16-18.

[24] 黄文典, 李 嘉, 邓 云. 含沙水体污染物生物降解反应动力学研究. 水科学进展, 2008, 19(5):635-639.

[25] 郭 儒, 李宇斌, 富 国. 河流中污染物衰减系数影响因素分析. 气象与环境学报, 2008, 24(1): 56-59.

[26] 国家环境保护总局《水和废水监测分析方法》编委会. 水和废水监测分析方法. 北京: 中国环境科学出版社, 2002.

[27] Branom JR, Sarkar D. Phosphorus bioavailability in sediments of a sludge-disposal lake. Environmental Geosciences, 2004, 11( 1$)$ : 42-52.

[28] 谭 县, 陈求稳, 毛劲乔等. 大清河河口水体自净能力实验. 生态学报, 2007, 11: 4736-4742.

[29] Zhou Q, Gibson CE, Zhu Y. Evaluation of phosphorus bioavailability in sediments of three contrasting lakes in China and the UK. Chemosphere, 2001, 42: 221-225.

[30] 李大鹏, 黄 勇. 太湖梅梁湾和月亮湾春夏两季沉积物扰动下 BAPP 的转化规律. 环境科学学报, 2013, 33(10): 2766-2773.

[31] Mulholland PJ, Helton AM, Poole GC et al. Stream denitrification across biomes and its response to anthropogenic nitrate loading. Nature, 2008, 452(7184): 202-205.

[32] Seitzinger S, Harrison JA, Böhlke JK et al. Denitrification across landscapes and waterscapes: A synthesis. Ecological Applications, 2006, 16(6) : 2064-2090.

[33] 郝建朝, 刘学增, 卢显芝等. $\mathrm{pH}$ 和沸石处理池塘底泥磷吸附与解吸行为的研究. 环境科学与技术, 2008, 31(8): $18-21$.

[34] 李大鹏, 黄 勇, 李伟光. 底泥再悬浮对不同营养水平上覆水中磷酸盐迁移的影响. 水处理技术, 2008, 34(6): 4-7.

[35] 余 晖, 张学青, 张 䂀等. 黄河水体颗粒物对硝化过程的影响研究. 环境科学学报, 2005, 24(4) : 601-606.

[36] WU QH, Zhang R, Huang S et al. Effects of bacteria on nitrogen and phosphorus release from river sediment. Journal of Environmental Sciences, 2008, 20(4) : 404-412.

[37] Bassin JP, Kleerebezem R, Dezotti M et al. Simultaneous nitrogen and phosphate removal in aerobic granular sludge reactors operated at different temperatures. Water Research, 2012, 46(12) : 3805-3816.

[38] 庞志华, 林方敏, 卢萃云等. 组合工艺修复受污染河水的模拟河道试验研究. 环境科学与技术, 2011, (S2): 83-87.

[39］田伟君，翟金波.生物膜技术在污染河道治理中的应用. 环境保护，2003，(8)：19-21.

[40] 喻治平, 赵智杰, 杨小毛. 人工快速渗滤池微生物活性的研究. 中国环境科学, 2005, 25(5): 589-593.

[41] 杨 否, 林逢凯, 胥 峥等. 底泥修复中温度对微生物活性和污染物释放的影响. 环境污染与防治, 2007,29 (1) : 22-25.

[42] Jensen HS, Andersen FO. Importance of temperature, nitrate, and $\mathrm{pH}$ for phosphate release from aerobic sediments of four shallow, eutrophic lakes. Limnology and Oceanography, 1992, 37(3) : 577-589.

[43] 汪家权, 孙亚敏, 钱家忠等. 巢湖底泥磷的释放模拟实验研究. 环境科学学报, 2002, 22(6) : 735-742. 